\title{
A new normal?: Women's experiences of biographical disruption and liminality following treatment for early stage breast cancer
}

\section{Abstract}

Increasing numbers of women are surviving breast cancer, but little is known about the long-term implications of having survived a lifethreatening illness and living with embodied reminders of its potential to return. Twenty-four women aged between 42 and 80 (median=51)who had been treated for early stage breast cancer in the UK between 6 months and 29 years previously, were recruited through local media and interviewed. Analysis of their narratives revealed challenges in the posttreatment period that were conceptualised as biographical disruption and liminality. Although no longer ill, an ongoing fear of recurrence combined with embodied changes prevented a return to 'normal' i.e. a pre-cancer state in terms of health status, identity and relationships. We argue that following the biographical disruption of breast cancer, a 'new normal' entails a continual renegotiation of identities, daily lives and futures as time passes and lives evolve.

Keywords: UK; breast cancer; biographical disruption; liminality; posttreatment; 'new normal' 


\section{Introduction}

Breast cancer is the most common type of cancer affecting women in the UK during their lifetime (Cancer Research UK, 2015a). It is diagnosed by clinicians as either primary (or early stage) meaning that it has not spread beyond the breast or lymph nodes, or secondary cancer (metastasis) where it has spread to another area of the body (e.g. lungs or bones), which is usually deemed incurable (Cancer Research UK, 2015b). Breast cancer differs from many illnesses in that, although there are many theories about its aetiology, the exact cause remains unknown. In addition, following treatment for primary breast cancer there is the possibility of recurrence and subsequent development of secondary breast cancer (Cancer Research UK, 2015c)

Encouragingly for those who are diagnosed with the condition, life expectancy has increased. Recent predictions suggest that $78 \%$ of women diagnosed with breast cancer in 2010/11 will survive more than ten years after treatment, compared with $40 \%$ forty years earlier (Cancer Research UK, 2015a). Consequently there is a need for greater understanding about the post-treatment period (Powers et al., 2014; Blows et al., 2012). Oncologist and academic Siddhartha Mukherjee argues that for a woman who has experienced breast cancer:

Cancer will become a chronic condition.. she will live in its immediate shadow for decades, never quite certain about her 
outcome... Having entered the world of cancer, her life will be permanently altered. For her, cancer will become the new "normal" (Mukherjee, 2011:27).

From a sociological perspective, the question then emerges of what constitutes this 'new normal'. In this study of women who were several years post-treatment for breast cancer, we consider the long-term implications of surviving a life-threatening illness and living with embodied reminders of treatments which include surgery to remove affected cells (lumpectomy), or the entire breast (mastectomy). The analysis presented here explores how women 'engage with and manage the myriad challenges' (Murray, 2015:91) in the post-treatment period, including living with fear of recurrence and the impact of bodily changes on perceptions of femininity and sexuality. This analysis furthers our understanding of what it is like to live in the afterlife (as opposed to the aftermath (see Roy, 2012)) of early breast cancer and its treatment.

\section{Background}

Bury's (1982) concept of illness as a biographical disruption, developed from a study of those with rheumatoid arthritis, has been highly influential in the study of experiences of illness. Bury argues that chronic illness disrupts normality and initiates a process of re-examining expectations for self, daily life, and future hopes and plans. Similarly, a cancer diagnosis can also often be experienced as biographical disruption 
(Balmer et al., 2015; Liamputtong \& Suwankhong, 2015; McKenzie \& Crouch, 2004). There are typically no obvious indications of breast cancer other than a lump in the breast tissue found either through selfexamination or breast screening. Although Liamputtong and Suwankhong (2015) suggest that biographical disruption can be instigated on first discovering symptoms, Holmberg (2014:179) observed during her fieldwork in a breast cancer clinic that 'it was the naming process that tore the women from their everyday lives.' Such a diagnosis is typically accompanied by a rapid transition to the 'sick role' (Parsons, 1951), where compliance with medical guidance is expected, and normal roles and responsibilities are suspended until health is restored.

A range of studies have also revealed particular challenges associated with the period following treatment for breast cancer, including: ongoing fears of recurrence (Costanzo et al., 2007); distress at the simultaneous loss of medical and social support (Allen et al., 2009); and emotional vulnerability (Powers et al. 2014), with potentially permanent effects on daily living. Furthermore, the physical consequences of breast cancer treatment can have long-term implications for identity, self-esteem, confidence, social relationships, body image and sexual relationships (e.g. McCann et al. 2010, Thomas-MacLean, 2005, Wilmoth, 2001).

Studies have suggested there is a need for ongoing care and support (such as counselling) to help women cope with changes to their bodies and relationships during the transition from treatment to 'normal' life. In 
this context, normality is equated with resumption of pre-cancer roles and self-management of breast cancer symptoms (Tighe et al., 2011;

Thomas-MacLean, 2005). However, this seems to suggest that a return to the previously lived 'normal' is possible whereas Balmer et al. (2015:468) argue that 'living after cancer is a persistently disruptive experience'. As such, it can be argued that patients can experience biographical disruption not only at point of diagnosis, but also when they leave the sick role and enter an interim state situated between being ill and being fully restored to a pre-diagnosis state of health. This interim state may be conceptualised as liminality (Powers et al., 2014; Blows et al., 2012; Crouch \& McKenzie, 2000).

The term liminality, adopted from anthropology, describes situations in which people find themselves 'betwixt and between' classifiable states (including states of health and illness) and is characterised by loss of status, ambiguity and marginality (Turner, 1969:95). Just as Thompson (2007:343) found that liminality was particularly useful for understanding experiences of ovarian cancer which can recur, leaving affected women 'in a perpetual state of uncertainty', we argue that it is also useful for understanding experiences of breast cancer due to the possibility of recurrence.

Despite the apparent suitability of the concept of liminality in understanding the post-cancer experience, a review of the literature which applies it in this context (Blows et al., 2012) found that most studies do not consider experiences beyond 5 years post-treatment. 
Furthermore, just one study was identified which focussed specifically on breast cancer (Crouch \& McKenzie, 2000) but only included 7 participants. Therefore, this study of 24 women who had completed treatment up to 29 years earlier enables a longer term and more in depth consideration of ongoing disruptions to identities, bodies and relationships, from diagnosis of breast cancer to the end of treatment, and well beyond. We argue that biographical disruption and liminality are useful concepts to apply in understanding the range of experiences associated with falling between states of illness and health, and having permanently altered bodies.

\section{Method}

The data presented in this paper are taken from a study conducted in the UK between 2009 and 2012 (Trusson, 2013a). The qualitative approach taken was consistent with the research aims of understanding and interpreting women's experiences of early breast cancer which often contain contradictions and inconsistencies that can be difficult to capture by quantitative means (Benton \& Craib, 2001). Furthermore, a narrative approach was deemed appropriate due to its suitability for studying the impact of change and disruptive episodes on people's lives (Murray, 2015). According to Murray (2015), narrative research in which people are encouraged to talk about their lives in their own words, can provide a way of restoring a sense of order when everyday lives are disrupted by events such as illness. 
After gaining University ethics approval, women who had been treated for early stage breast cancer were invited to participate in the study via a University website and local media. This method of recruitment had the benefit of enabling access to women who had completed hospital-based treatment and who otherwise would have been difficult to reach. Details of the sample are in Table 1 below:

[Table 1 -sample characteristics here]

Participants were interviewed in depth at a place of their choosing. Interviews which were conducted in participants' own homes tended to be longer and more in-depth, possibly because, as Finch (1993) found in her research, the participant was in an environment where she felt comfortable telling her story and the interviewer was perceived as a 'friendly guest.'

After explaining the purpose of the study, signed consent was gained from the participants, who had the opportunity to choose a pseudonym. However, some eschewed anonymity, preferring as Jean (aged 75) put it, to 'stand up and be counted'. For these participants it seemed that anonymity could be seen as disempowerment.

Each interview started by asking participants how they first discovered that they had breast cancer. Although they were encouraged to tell their stories in whatever way they wished, a series of prompts was used to stimulate discussion. For example, participants were asked about the impact of their diagnosis on relationships (with families, friends, work colleagues etc.) and the adaptations needed to cope with bodily changes 
(Conrad, 1990). This meant that participants were able to include any information that they wanted to talk about, whilst ensuring some commonalities between their narratives. Interviews lasted between 1 and 4 hours and were digitally recorded and transcribed in full.

\section{Reflexivity}

Interviews were conducted by the first author (DT), who drew on her own breast cancer experiences, though these were only revealed once the participant had finished narrating her own story. Johnson (2009) used a similar approach in her study of familial breast cancer, arguing that her personal experience increased empathy. (In contrast, Jain (2013) admits that she sometimes omits her own breast cancer experiences when giving talks, lest she be considered non-objective. Consequently she is sometimes treated as an outsider by some survivors who are sceptical of analysis of their experiences by academics that are presumed not to have actually had breast cancer themselves).

After the interviewer disclosed her status, the interview became more conversational, with some participants reporting that they felt able to talk about experiences and emotions that they were uncomfortable discussing with their friends and family. Although the benefit of talking to someone outside of the interviewee's social circle has previously been noted (e.g. Finch, 1993), it may be still be difficult to discuss certain aspects of the experience with people who have not been through similar things. 
Therefore the resulting data were perhaps deeper than might otherwise have been possible to gather, as Johnson (2009) also found. The ethical dilemma of whether this approach encouraged women to reveal more than they otherwise might have (Finch, 1993) was addressed by confirming consent at the end of the interview.

\section{Analysis}

The process of analysis was informed by Murray (2015) who describes two broad phases: firstly descriptive and secondly interpretive, which entails reading narratives several times to enable familiarity with their structure and content. In this paper we focus on the content of the narrative, i.e. on "what" is said, rather than "how", "to whom", or "for what purposes"' (Riessman, 2008:53-4).

Close reading of the narratives enabled connections to be made between emergent ideas from the data and the relevant literature (Murray, 2015). Although each experience was individual, there were common experiences which were compared with those of other participants, as well as to existing literature. The findings and interpretations were discussed with the co-authors to enhance reliability of the analysis (Mays \& Pope, 1995) and resulting themes are presented in the following section. For further details of the methodology, see Trusson (2013b). 


\section{Findings}

Analysis of the women's narratives revealed some common themes within their individual stories. We begin this section by discussing participants' experiences of diagnosis and then move on to describe how finishing formal treatment can also be disruptive. We then discuss ongoing disruptions in the post-treatment period due to persistent fears of recurrence and embodied reminders of treatments, and how these can affect identities and relationships. Finally, we discuss ways in which participants described changes in their outlook since surviving a lifethreatening illness.

\section{Biographical disruption and liminality}

Human lives are in a constant state of flux, and disruptions can occur for a variety of reasons, some of which emerged in the participants' stories. The wider study (Trusson, 2013a) revealed disruptions before and after diagnosis, as well as some cases where diagnosis was not disruptive but a biographical continuity (as Williams (2000) found). However, discussion of these cases is beyond the scope of this paper which focusses on the experiences of the majority of participants for whom diagnosis had come completely out of the blue as the following quotes illustrate:

I was shocked because I thought well why me? Especially that I'd lived a life of nothing wrong with me at all. I'd been so fit. (Joy, 63) 
It just shatters you completely. Just everything, everything alters.

Your whole life sort of thing. (Barbara, 61)

For these participants who felt 'healthy' but discovered they were ill, diagnosis disrupted their view of themselves and initiated 'a fundamental change of the women's lives based on a new understanding of their (physical-biological) bodies' (Holmberg, 2014:178). There were also implications for relationships. For example, one woman said that she had previously considered herself the 'healthy one' in her marriage:

My husband has been ill for a long time so it knocks all that sideways. You can no longer think of yourself as a healthy person. (Martha (58), 8 years post-treatment)

Martha's loss of confidence in her healthy status had disrupted her marital role and seemingly increased both Martha and her husband's vulnerability. As such, the quote illustrates Janoff-Bulman's (1992) argument that a diagnosis of illness can shatter previously held assumptions of indestructibility and security. Another participant described her experience as follows:

I remember thinking; 'life really does begin at 40 . Beth's getting a bit more independent, so I can start thinking about myself now, You know, its hard work bringing up a child on your own but I did it and I thought, 'it's my time now.' And then 11 months later I was diagnosed with cancer! (Sam (42), 2 years post-treatment) Sam's comments suggest that she felt she deserved a chance to improve her life following difficult circumstances, yet her experience of breast 
cancer had removed her sense of optimism. This illustrates the sense of unfairness often associated with diagnosis, as life takes on a different trajectory as a result of being ill (Bury, 1982).

Whilst diagnosis marked the participants' transition into the sick role, their narratives also revealed that the end of treatment could be equally disruptive. For example, Ruth reported that she had 'terrible depression' afterwards:

I think it was when normality resumed really ... instead of having all this wonderful nursing care, like the district nurse popping round, going into hospital and being treated like an invalid, ... Suddenly all that starts to fall away. (Ruth (59), 4 years post-treatment) It seems that Ruth's daily life in the sick role was disrupted when treatment ended and she expressed a sense of abandonment at having to cope without medical surveillance. Phoebe reported similar disturbance:

It was quite nice people fussing round you. In fact you have to sort of adjust afterwards when you get back to work and it's like normal life again. Because it's not really normal is it? It took me a long while to adjust to the daily grind and mundane things. Cus you live in a little bubble while it's all happening. (Phoebe (45), 6 years post-treatment)

For these women, the disruption caused by the end of medical treatment revealed vulnerability at the loss of medical and social support associated with the sick role. This reaction has been noted previously in research by 
Allen et al. (2009) whose participants reported increased distress after their cancer treatment finished and, like Ruth and Phoebe, some were subsequently treated for depression. It seemed that returning to roles held before their diagnosis had 'made stark' the realisation that a return to the 'old normal' was not possible (Balmer et al., 2015:466) as Ruth went on to say:

I think going back to work helped, helped me through it definitely. Get back to normal then, some sort of normality.

Interviewer: Was it normal though?

Ruth: Well there's a little bit of that, returning to some sort of normality but there's also quite a lot of being left and, you know nothing's changed, you've moved on and they haven't. So it's a strange sort of in-between time I think is the problem.

Although Ruth's return to her work as a teacher had resulted in resumption of certain aspects of her pre-cancer life, she acknowledged a tension; that she felt that her life had altered in fundamental ways whilst at the same time (in terms of her job and her colleagues) 'nothing's changed' which is suggestive of liminality.

The delayed reaction to breast cancer treatment was echoed by other participants including Andrea:

I got through it but then there was an issue, you know, what happens after that? It was a real shock and it took a number of years before it began to gather, you know, the impact. (Andrea (64) 7 years post-treatment) 
This quote reveals the potential for breast cancer to be traumatic with a consequent uneasiness and uncertainty in the post-treatment period which actually grows rather than lessens with time. A simultaneous mixture of moods and emotions may combine in a disconcerting experience (McKenzie \& Crouch, 2004) as Barbara expressed:

Yes I am over the moon to be alive but then [pause] I'm also very sad. Yes. Deep down sad. I was told that life would never be the same again and it isn't. It isn't the same. (Barbara (61), 5 years post-treatment)

Barbara seems to be mourning the loss of her former life, former body and former sense of optimism. These losses are interpreted as constituting biographical disruption because Barbara reported that she had been looking forward to life opportunities created by her husband's retirement. However, her unexpected diagnosis had left her feeling that it was not possible to return to life as it was, or anticipated it would be, but instead found herself in an ambiguous, liminal state.

This section has shown how biographical disruption is not a finite event but an ongoing process as Balmer et al. (2015) suggest. This indicates important differences between the current study and Bury's (1982) original conception of biographical disruption in his study of experiences of diagnosis of a worsening chronic condition (rheumatoid arthritis) that rendered his participants permanently in the sick role. In contrast, the participants in the current study had completed treatment for early breast cancer and were no longer perceived by the medical profession to be ill. 
However, they experienced further disruption at the end of treatment and subsequently described feeling different from both their pre-illness state and their sick state, which engendered ambiguous feelings associated with liminality. In addition, the possibility of recurrence, either in the same or other breast, or as secondary cancer elsewhere in the body sometimes created a perception of never being fully cured, as will now be discussed.

\section{Fear of recurrence}

One of the reasons why participants seemed to be in an ambiguous state was that despite having completed treatment, they were aware that the cancer could potentially return. Three participants had actually experienced a recurrence. Betty (80) who was treated 20 years and 12 years previously, was beyond the age where she would be invited for routine breast screening (NICE, 2015), but apparently sought reassurance by requesting regular tests. The other two women had elected for double mastectomy to prevent another recurrence of cancer in their breast, although they knew that cancer could still recur elsewhere in their body. Jean (75) who was diagnosed 29 years and 5 years previously, said:

It never goes away. You get on with your life and you have to deal with it but there's no guarantee; there can't be.

This indicates a change of mental state where the fear of recurrence was ever-present, even after a number of years. It was identified as a 
common theme amongst the majority of the participants, as the following quotes illustrate:

I always think about it coming back, I think about that all the time. I had backache about 6 months ago. The doctor gave me an x-ray just in case it spread. But it hadn't. But that's the first thing you think..I suppose that's what it's gonna be like for the rest of your life. (Viv (44), 4 years post-treatment)

If I get like a pain somewhere else I'm like 'oh my god has it shifted?' (Sophie, (49), 6 years post-treatment)

These accounts suggest a constant state of hyper-vigilance which is particularly understandable given that women are expected to selfmonitor for early signs of cancer. Like Thompson's (2007) participants who feared cancer recurrence, women in this study expressed difficulty in judging whether symptoms were 'normal' or cause for concern.

The experiences of women in this study suggest that after cancer, people may no longer have a sense of security in their body because 'it has become a potentially hostile object that has gone seriously wrong, and could do so again' (Little et al., 2000:501). Joy expressed anxiety about her first annual check-up in these terms:

I do worry a little bit about August because I thought 'oh God, it'll be my luck', you know. I thought I might change it to September because we'd like to do something for Ben's birthday but I thought 'ooh you might regret it if you postpone it'. (Joy (63), 6 months post-treatment) 
Despite having no specific physiological reason to suspect a cancer recurrence, Joy's anxiety is impacting on her plans for family events. However, the narratives of women who were longer post-treatment suggested that this might diminish over time, as Barbara illustrated:

At one time I couldn't book a holiday or book something months in advance, cus that frightened me. I couldn't look forward to something I might not be able to enjoy. That's gone now. I just think 'oh sod it! If I can't go, I can't go.' [laughs] (Barbara (61) 5 years post-treatment)

Although no straightforward links were found between post-treatment times and fear of recurrence, there were subtle changes such as stopping putting plans on hold as Barbara's comments illustrate. Nevertheless, fear of recurrence never seemed to be far from the surface. Barbara was one of several participants who described how media coverage sometimes reminded them of their precarious health status:

It's in the papers all the time, somebody that's got it or recovering from it and I find that quite difficult to cope with. And it's good, because it makes people aware of it, but it isn't always good for everybody...it's just reading about things 'thought she'd got over it' you know 'its 5 years then a month later she drops dead'. Those sorts of things really bug me. They really sort of eat into you somehow. 
Barbara's mention of 5 years is significant because not only did this correspond with her post-treatment period; it is a point at which survival time is measured (Cancer Research UK, 2015d). Therefore some participants seemed to regard this as a milestone after which they could relax somewhat about recurrence, though never entirely, as previously discussed.

Taken together, the reported experiences of women in this study indicate that the end of treatment does not mean a return to a pre-illness state but instead, as Little et al. (2000:501) argue, 'cancer survivors pass through the space of illness but do not emerge back into a world which is normal in the sense that it is the same as before the illness.' Karen expressed this feeling succinctly:

There's a new normal isn't there? There's definitely a 'new normal' because it's always gonna be there. I don't think about breast cancer every day, I know some women do, but it will always be there. (Karen (43), 6 months post-treatment)

Karen's comments suggest that the fear of recurrence was a facet of the liminal ('new normal') experience which was in flux; it was constantly below the surface and could re-emerge at any time.

In the following section we discuss how breast cancer treatments leave embodied reminders that a return to the 'old normal' self is not possible (Balmer, 2015). 


\section{Embodied reminders}

Even if participants could reconcile their fear of recurrence, they still had physical reminders of their treatment. Some participants described tattoos and burn marks from radiotherapy; others complained of weight gain resulting from hormone therapy. In addition, all of the participants had lost either part, or the whole, of one or both breasts. Phoebe (45), who had a mastectomy 6 years previously commented:

It's something you can never ever forget 'cus there's this constant reminder.

Breast loss was a permanent embodied reminder 'that they were now different, that they had experienced illness, that their stories had been irrevocably altered' (Thomas-MacLean, 2005:207). However, in contrast with the existing literature, for the women in this study this difference was not always experienced wholly negatively. Barbara (61) put a positive spin on it, saying:

I can't believe that I've had it now. I can't believe that it happened to me. But I've always got that reminder. I went through all that.

Me! I did it! It's something to be proud of in a funny sort of way. Barbara's comments are reminiscent of how battle scars are sometimes considered a source of pride. Yet her comments also exemplify ambiguity because Barbara was simultaneously 'proud' of her scars and (elsewhere 
in her narrative) distressed at the negative impact on her sense of femininity and sexuality (as discussed later in this paper). Some participants experienced bodily difference in terms of gendered identity such as Catherine (47), who described her post-mastectomy body:

It was like having grown up as a woman and then, all of a sudden, look down and see your tummy again! Look like a little boy on one side [laughs]

Catherine's view of herself as a woman had been disrupted by surgery, highlighting the importance of breasts to a feminine appearance. As Jain (2013:82) argues, 'mastectomy scars cite the amputation of gender, at once undermining nurturance and sexuality'. Although Catherine did not seem unduly upset in her description, Young (1990) suggests that most women find mastectomy extremely traumatic because breasts are heavily implicated in their identity. Sam (42), who had a mastectomy 2 years previously said:

I'm not able to wear a lot of my clothes. I've lost a lot of confidence, my self-esteem..it's very upsetting actually. I mean I get up in the morning and have a shower and get dressed and that kind of thing. You put your mask on really. I always do my hair and make up to make myself feel better. It's like a ritual really to try and create an illusion. But I don't like it; I find it difficult to look at myself in the mirror put it that way. Because I was so fit and healthy and vivacious. My friends used to say I was the glamorous 
one and all that.. And I feel like I've lost a certain part of that, I really do.

Clearly, Sam's treatment constituted much more than the loss of a body part because it had profoundly affected her sense of identity and she seemed to be mourning her previous persona. In clear echoes of Goffman (1959) Sam described the considerable effort involved in pretending to be as she once was, yet never fully succeeding. As Goffman (1959:28) points out, 'the performer may not be taken in at all by his own routine' and Sam remained aware that it was a façade, or as she described it, 'an illusion'.

Sam's account demonstrated that in the post-treatment period, even the 'everyday act of clothing oneself was imbued with new meaning' (Thomas-MacLean, 2005:204). Several other participants described the measures they took to conceal the results of surgery, such as avoiding low necklines which might reveal a scar or the top of their prosthesis, and avoiding certain situations, as Maggie described:

I don't like looking at myself in the mirror now, at least not that part. I'm very conscious of even my husband or kids seeing it, or anybody else for that matter. I would never go into a communal changing room, somewhere like that..A friend was having a group of friends to go to one of these spa places for the day and I declined because although they knew, I just didn't feel confident about it. (Maggie (56), 7 years post-treatment). 
This illustrates disruption to social activities where the opportunity of a spa day with friends, which would normally be considered a treat, instead became a source of anxiety. Maggie expressed a certain amount of shame which Bartky (1990:86) describes as 'the distressed apprehension of the self as inadequate or diminished,' and she seemed worried that this inadequacy 'may come suddenly and horribly to light' (Bartky, 1990:86). Connie (51) reported such an incident at a public swimming pool:

One day the bolt was broken on the door and midway through getting changed some teenagers opened the door and they thought it was hilarious..that was a tough experience.

Connie's embarrassment that her post-surgery body had been seen (and laughed at) was compounded because it happened at a place where, before her surgery, she had worked in a position of authority as a swimming instructor. This humiliation, coupled with a loss of status, is characteristic of liminality (Turner, 1969) and in this context it can also be viewed as a biographical disruption because swimming had previously been central to Connie's identity.

This section has revealed how women's everyday lives were disrupted by bodily changes which involved careful management of their appearance and impacted on social activities. Having all undergone breast surgery as part of their treatment, each participant reflected on what their breasts meant to their identity which, to various extents, affected their ability to adapt to life after breast cancer. We will now continue this discussion by 
exploring the implications of bodily changes for current and potential intimate relationships.

\section{Relationships}

While participants strove to sustain the pretence of 'normality' in social situations, this was not achievable in intimate situations as these participants described:

You look alright clothed, but not undressed you don't. It's awful. [Long pause] My husband tries to be nice about it but you know you look like a freak..I don't get changed in front of him. If he comes in the room I just put my back to him. And he's like 'oh no its fine' but [pause] it's not. (Viv (44), 4 years post-treatment)

It's changed me. It changes how I feel sexually because it's quite a big part and yes, that part changed. Because [pause] I don't, I don't feel attractive any more. And that I find upsetting. (Barbara (61), 5 years post-treatment)

These extracts indicate the importance of breasts to self-perceptions of sexual desirability and body confidence. Findings suggest that female bodily insecurities emanating from societal expectations for bodily perfection (Bordo, 2003) are magnified for women who had undergone surgery for breast cancer. Furthermore, participants seemed to be affected by losing a breast whatever their age. This finding is echoed by Neises et al. (1994) who measured facets of quality of life including 
sexuality, body image, and femininity in women following mastectomy. They found that those aged $60+$, who comprised half their sample, reported significantly lower scores than their younger counterparts and, like Barbara, expressed incomplete womanhood.

Other participants echoed Barbara's distress at having to adjust to a new sexual self in the wake of disruption to their appearance and described the impact on their intimate relationships. Connie (51) who had had a mastectomy 7 years previously, was particularly candid:

Being really personal, behind the bedroom door, don't let anyone tell you that it doesn't alter things because it does. Absolutely does. Interviewer: In what way?

Connie: In the way you feel.

This is notable because in Connie's account, it is not the physical loss of a breast that has impacted on her relationship with her husband, but instead the way she feels about herself which indicates the mental and emotional aspects of sexuality. Similarly, Wilmoth (2001) found that selfesteem and body image had a more detrimental effect on her participants' sexuality than menopausal symptoms. This contrasts with most research into sexuality after breast cancer which takes frequency of sexual intercourse as a proxy. As Wilmoth (2001) argues, this is a measure based on male ideas of sexual satisfaction, and as the data here show, the reality may be much more nuanced for women. 
However, and despite the significance of loss of a breast described in previous literature, some women in this study rejected the centrality of their breasts for maintaining a loving relationship:

Well I've been married blooming 40 odd years now; you know your body does change anyway. (Joy (63), 6 months post-treatment) I'm not that bothered. And if it bothered him I think that would be slightly worrying, it would indicate to me that there were problems in the relationship if that was all that was attracting him, you know. (Ruth (59), 4 years post-treatment)

I said, "it's definitely cancer, duck, and I'm going to have a mastectomy, will you still love me?" [laughs] He says "do what you want duck. You know that". (June (73), 8 years post-treatment) Joy seemed to accept as inevitable that her body would change as she grew older and, like Ruth, alluded to the role of breasts in sexual desire. June recalled her conversation with her husband (in which both used a colloquially affectionate term, 'duck'), to show how, like Joy and Ruth, their loving relationship transcended the physical aspects. However, a different set of issues arose for the women in the study who were not in an established relationship as Malaika described:

I joined a dating agency and I thought I needed to tell everyone straight away that I'd only got one breast [laughs] and that way they don't have to see me again. But my mum said "you're probably shocking the poor buggers!" I said "Well at what stage do you tell 
them? You know, it's not something I'm practiced at. How do I know when to tell them?" (Malaika (45), 6 years post-treatment) Unlike many of the participants who had partners, single women were faced with a dilemma of having to decide if and when to 'expose disfigurement..of that part of the body which is most closely associated with the representation of femininity and feminine sexuality' (Crouch \& McKenzie, 2000:204). This had become problematic for single-parent Sam (42), who had been waiting for reconstructive surgery since her mastectomy 2 years previously:

I'm stuck. I'm single, I can't even think about getting a partner with the way that my body is at the moment because fellas are shallow at the best of times without having to explain to someone that I've only got one boob.

This indicates the importance of Sam's physical appearance to her selfesteem and confidence as well as her opinion that men are similarly driven by appearances. Sam was clearly frustrated at being in limbo whilst waiting for reconstructive surgery which she believed would restore her body confidence sufficiently to seek a relationship without fear of rejection.

However, one of the limitations of the current study is that it only included four single women, only two of whom were seeking a heterosexual relationship. Of the others, one was widowed, and claimed that losing her breasts was not a major issue because: 
When you get to 80 you're not wanting to er [laughs] you know chase round the fellas sort of thing! (Betty (80), 20 years posttreatment)

The second woman in this category identified as a lesbian, and described bodily changes as much less of a problem than for some of the other participants:

This is another issue about me being a lesbian, I don't wear women's clothes, I look like this all the time. For me it wasn't that different, it wasn't an appearance issue. I feel better like this. (Andrea (63), 7 years post-treatment) It seems that Andrea's identity was affected to a lesser extent by the loss of her breasts because she did not regard them as crucial to her particular gender performance. Similarly, Jain (2013:20) who describes herself as 'an out queer' reflected on having her remaining (healthy) breast removed following her first mastectomy, that 'breasts had forced me to live in a sort of social drag' (Jain, 2013:75). Although it is difficult to make generalisations based on the experiences of the four single women in the study, their experiences raise interesting issues which merit further research.

Our findings revealed no significant patterns to suggest that age played a role in how women felt about their changed body. Instead, the extent to which participants were traumatized or accepting of their post-treatment bodies seemed to depend on the way that they perceived their breasts in relation to their identity and/or relationships. 
We now move on to consider changes in outlook and implications for identity in the post-treatment period.

\section{Changes in outlook}

This paper has so far shown the disruption of an unexpected breast cancer diagnosis on participants' identities, daily lives and expectations for the future. However, findings revealed various ways in which these were renegotiated in the wake of breast cancer treatment. Turner $(1967: 106)$ argues that the liminal state can be an opportunity to reflect on what is important; to question norms and assumptions, and with a certain freedom to 'juggle with the factors of existence'. A common theme in the participant's narratives was that their experience of breast cancer had made them rethink their lives, as below:

You have to take yourself anew don't you? You definitely do not feel in any shape or form the sort of person who you were before. You've been chucked up in the air and you come back down again and everything's different, it feels to me. (Catherine (47), 2 years post-treatment)

Not only does Catherine eloquently describe the biographical disruption of breast cancer as being 'chucked up in the air', her narrative also has clear parallels with Turner's (1969:103) description of the liminal subject as a 'blank slate'; being prepared for a new stage in their life. In terms of identity construction, it suggests that for some participants their 
experience of breast cancer could also mean creating a new 'self,' as Gabrielle and Jean suggest:

I saw it as an opportunity to start from scratch. (Gabrielle (45), 3 years post-treatment)

I often think it made me a better person. And I've done more since I had it than I did before, for sure (Jean (75), 29 years posttreatment)

Like Jean, many participants reported changes to their self-identification as a result of their encounter with a potentially fatal disease:

It's like opened the door on my own mortality and I've looked in and thought "actually I'm okay with that now". So it made me appreciate my friends, my husband, my life.. um I'd like to say it changed my life so much that I now only do things that I really like doing, but I haven't! (Sophie (49), 6 years post-treatment)

Sophie's description indicates a shift in perception; focusing on what she has, rather than what she has lost. This appreciation for previously takenfor-granted people and relationships is characteristic of the liminal period (Turner, 1967) and is sometimes referred to as posttraumatic growth (see Koutrouli et al., 2012). Although Sophie's change in outlook had not impacted significantly on her behaviour, some participants reported that their breast cancer experience had given them a different perspective on how they should use their time:

I think it makes you realise that if you want to do anything you've got to get on and do it. (Ruth (59), 4 years post-treatment) 
The experience of biographical disruption had led Ruth to make the most of her current 'healthy' status rather than defer plans until a time that may never come. As Thompson (2007) suggests, liminality is not always experienced as constraining and in Ruth's case the possibility of recurrence (discussed earlier), had given her the impetus to 'seize the day'.

For some of the participants, change was unavoidable due to the physical effects of their treatments. For example (as previously mentioned) Connie's mastectomy had reduced her strength and mobility, preventing her from resuming work as a swimming instructor. In line with many other cancer survivors who 'feel the need to reassess attitudes, values and goals' (McKenzie \& Crouch, 2004:147), Connie said:

When you've just been hit with the hardest bullet of your life, you need a positive.. My friend and I, she'd walked in my shoes a couple of years previous, and we decided we wanted to give something back and we've now raised thousands for patient care. (Connie (51), 7 years post-treatment)

This indicates the fluidity of identity: having lost her pre-illness identity as a swimming instructor, Connie had embraced a new role within the cancer fundraising community, strengthening her 'sense of self and well-being' and providing a new way of identifying herself (Roger et al., 2014:7). Like Connie, many other participants retained some aspects of the cancer identity in order to identify with, and support, other women going through a similar experience. Indeed, all the participants indicated that this was 
their reason for volunteering to take part in this study. Volunteering also seemed to be a way of regaining some agency, as in Sam's case where, as discussed previously, the stagnation of her situation had prevented her making desired changes to her life. Nevertheless, in an act of what Little et al. (2000:501) describe as 'altruistic adaptation' to the liminal experience of survivorship, Sam volunteered as a patient ambassador to advocate for better care. Similarly, Andrea was using her teaching experience to train volunteers for a breast cancer charity and to highlight the particular needs of lesbian women undergoing treatment. Such altruistic adaptations provide meaning within the experience of illness which, Bury (1982) argues, is a way of coping with biographical disruption.

\section{Conclusion}

Our analysis of the narratives in this study has revealed the complex nature of the post-treatment period where emotions range from fear, anger and disappointment to gratitude, hope, and joy. Importantly, the narratives suggest that these emotions do not dissipate with the passage of time. The study draws on Bury's (1982) concept of biographical disruption to suggest ongoing disruption to lives and identities during the post-treatment period and supports previous research that highlights difficulties in establishing a new normal (Balmer et al., 2015). However, whilst Balmer et al. (2015) suggest that survivorship is experienced as 
ambiguous by people with poor prognosis cancers, we found similar ambiguity in the narratives of women who had apparently been successfully treated for early breast cancer. Happiness and relief at having survived a life-threatening illness were tempered by fear of a possible recurrence which 'ruptures the (usually) taken for granted 'normal' life course' (McKenzie \& Crouch, 2004: 140-1). Although no longer classified as ill, they felt unable to describe themselves as healthy in the same way as before their diagnosis.

This state of ambiguity and uncertainty has been described as liminality because women post-treatment are between states in which they can be easily classified. Although the concept of liminality has been used in previous studies of illness experiences, particularly cancer (e.g. Thompson, 2007), the current study adds a focus on breast cancer and the inclusion of 24 participants, 14 of whom were more than 5 years posttreatment. It therefore contributes to the sparse literature which employs the concept of liminality to explore experiences of long-term cancer survivorship (Blows et al., 2012) and also literature exploring biographical disruption beyond one year of cancer diagnosis (Balmer et al., 2015). Specifically, the findings revealed how permanent bodily changes resulting from breast surgery necessitate management of appearance on a day-to-day basis and can have long-term implications for identity and self-confidence, as well as current and potential relationships. Finally, whilst not denying the negative aspects of their experiences, it seems that for some participants the post-treatment period could also be 
a time of positive change, indicating the (often neglected) transformative aspects of liminality (Blows et al., 2012) and increasing our understanding of the 'subjective experience of a greater appreciation of life after a cancer diagnosis' (Balmer et al., 2015:466).

In summary, the data analysed here have shed empirical light on the challenges and opportunities experienced by women following the biographical disruption of diagnosis and treatment for early breast cancer. Our findings suggest ongoing disruption and perpetual liminality in the post-treatment period. Therefore we argue that rather than being an achievable state, a 'new normal' for our participants is a continual process of renegotiation of identities, daily lives and futures as time passes and lives evolve.

\section{Future research and limitations}

The study, whilst rich in its data, is limited by the cultural homogeneity and relatively small number of the participants. We have focussed on the impact of breast cancer treatment spanning the post-treatment period of participants who were diagnosed between 6 months and 29 years previously. Future research might seek to study groups of women who are within a more defined post-treatment timespan and/or compare experiences across timespans. The study has also highlighted important aspects of the post-treatment period that are worthy of further research, 
particularly if a more diverse sample in terms of ethnicity, sexuality, and relationship status was obtained.

\section{Acknowledgements}

We wish to thank all of the women who took part in this study and so generously shared their stories. We are also grateful to the three anonymous reviewers for their helpful comments on previous versions of this manuscript.

This work was supported by a Mildred Blaxter Post-Doctoral Fellowship from the Foundation for the Sociology of Health and Illness.

\section{References}

Allen, J.D., Savadatti, S. and Levy, A.G., (2009). The transition from breast cancer 'patient' to 'survivor' Psycho-Oncology, 18, 71-78

Balmer, C., Griffiths, F. and Dunn, J. (2015). A 'new normal': Exploring the disruption of a poor prognostic cancer diagnosis using interviews and participant-produced photographs. Health, 19(5), 451-472 Bartky, S.L. (1990), Femininity and Domination: Studies in the Phenomenology of Oppression, New York: Routledge

Benton, T. and Craib, I. (2001). Philosophy of Social Science: The Philosophical Foundations of Social Thought, Basingstoke: Palgrave 
Blows, E., Bird, L., Seymour, J. and Cox, K. (2012). Liminality as a framework for understanding the experience of cancer survivorship: a literature review. Journal of Advanced Nursing, 68(10), 2155-2164 Bordo, S. (2003). Unbearable Weight: Feminism, Western Culture and the Body, Berkeley: University of California Press

Bury, M. (1982). Chronic illness as biographical disruption, Sociology of Health \& Illness, 4(2), 167-182

\section{Cancer Research UK:}

a. http://www.cancerresearchuk.org/cancerinfo/cancerstats/incidence/commoncancers/\#Top3 accessed $22 / 9 / 2015$

b. http://www.cancerresearchuk.org/cancer-help/type/breastcancer/secondary/about/what-is-secondary-breast-cancer accessed $\underline{22 / 9 / 2015}$

c. http://www.cancerresearchuk.org/cancer-help/type/breastcancer/treatment/if-your-cancer-comes-back-after-treatment accessed 22/9/2015

d. http://www.cancerresearchuk.org/health-professional/cancerstatistics/statistics-by-cancer-type/breast-cancer\#heading-Two accessed 22/9/2015 
Conrad, P. (1990). Qualitative research on chronic illness: A commentary on method and conceptual development, Social Science \& Medicine, 30(11), 1257-1263

\section{Costanzo, E.S., Lutgendorf, S.K., Mattes, M.L., Trehan, S.,} Robinson, C.B., Tewfik, F. and Roman, S.L. (2007). Adjusting to life after treatment: distress and quality of life following treatment for breast cancer. British Journal of Cancer, 97, 1625-1631

Crouch, M. and McKenzie, H. (2000). Social realities of loss and suffering following mastectomy. Health, 4(2), 196-215

Finch, J., (1993). 'It's great to have someone to talk to': Ethics and Politics of Interviewing Women in Hammersley, M. (Ed.), Social Research: Philosophy, Politics and Practice (pp. 200-225). London: Sage Goffman, E. (1959). The Presentation of Self in Everyday Life. Harmondsworth: Penguin

Holmberg, C. (2014). No One Sees the Fear: Becoming Diseased Before Becoming Ill - Being Diagnosed With Breast Cancer. Cancer Nursing, $37(3) 175-183$

Jain, S. L. (2013). Malignant: How Cancer Becomes Us. Berkeley: University of California Press

Janoff-Bulman, R. (1992). Shattered Assumptions: Towards a New Psychology of Trauma. New York: The Free Press

Johnson, N., (2009).

http://www.researchgate.net/profile/Nicole Johnson10/publication/23665 1285 The role of self and emotion within qualitative sensitive resear 


\section{$\underline{13 / 9 / 2015}$}

Koutrouli, N., Anagnostopoulos, F. and Potamianos, G., (2012).

Posttraumatic Stress Disorder and Posttraumatic Growth in Breast Cancer Patients: A Systematic Review. Women \& Health, ⒉(5), 503-516 Liamputtong, P. and Suwankhong, D., (2015). Breast cancer diagnosis: biographical disruption, emotional experiences and strategic management in Thai women with breast cancer. Sociology of Health \& IIlness. 37(7), 1086-1101

Little, M., Sayers, E-J., Paul, K. and Jordens, C.F.C. (2000). On surviving cancer. Journal of the Royal Society of Medicine, 93(10), 501-2 McCann, L., Illingworth,N., Wengström,Y., Hubbard, G. and Kearney, N. (2010). Transitional experiences of women with breast cancer within the first year following diagnosis. Journal of Clinical Nursing, $19,13-14$

McKenzie, H. and Crouch, M. (2004). Discordant feelings in the lifeworld of cancer survivors, Health, 8(2), 139-157

Mays, N. and Pope, C. (1995). Qualitative Research: Rigour and qualitative research, BMJ, http://www.bmj.com/content/311/6997/109 accessed 13/9/2015

Mukherjee, S. (2011). 'Cancer: The new normal?' Guardian Weekend, $15 / 11 / 2011$ 
Murray, M. (2015). Narrative psychology. In Smith, J.A. (ed.), Qualitative Psychology: A Practical Guide to Research Methods, Third Edition, (pp.85-107). London: Sage.

National Institute for Health and Care Excellence (NICE) (2015).

https://www.nice.org.uk/guidance/cg80/chapter/1-Guidance accessed

\section{$9 / 9 / 2015$}

Neises,M., Sabok, M., Strittmatter, H-J., Wischnik, A., Melchert, F., (1994). Influence of Age and of Different Operative Methods on the Quality of Life in Patients with Breast Cancer. Onkologie, 17(4), 410-419 Parsons, T. (1951). The Social System, London: Routledge and Kegan Paul

Powers, N., Gullifer, J. and Shaw, R. (2014). When the treatment stops: A qualitative study of life post breast cancer treatment. Journal of Health Psychology

http://hpq.sagepub.com/content/early/2014/10/16/1359105314553963.f ull.pdf+html accessed 1/10/2015

Riessman. C. K. (2008). Narrative Methods for the Human Sciences, London: Sage

Roger, K., Wetzel, M., Hutchinson, S., Packer, T. and Versnel, J. (2014). "How can I still be me?" Strategies to maintain a sense of self in the context of a neurological condition. Qualitative Studies on Health and Well-being, 9, 1-10 
Roy, S. (2012). Remembering revolution: gender, violence, and subjectivity in India's Naxalbari movement. Oxford: Oxford University Press.

Thomas-MacLean, R. (2005). Beyond dichotomies of health and illness: life after breast cancer. Nursing Inquiry, 12(3), 200-209

Thompson, K. (2007). Liminality as a Descriptor for the Cancer Experience. Illness, Crisis \& Loss, 15(4), 333-351

Tighe, M., Molassiotis, A., Morris, J. and Richardson, J. (2011). Coping, meaning and symptom experience: A narrative approach to the overwhelming impacts of breast cancer in the first year following diagnosis. European Journal of Oncology Nursing 15, 226-232 Trusson, D. (2013a). Living with a new normal: women's experiences following treatment for early-stage breast cancer or DCIS (Doctoral dissertation, University of Nottingham).

Trusson, D. (2013b). Narrative Research: Women's Experiences Following Treatment for Early Stage Breast Cancer in 21st-Century Britain. In SAGE Research Methods Cases. London, United Kingdom: SAGE Publications, Ltd.

\section{http://dx.doi.org/10.4135/978144627305013509936}

Turner, V. (1967). The Forest of Symbols: Aspects of Ndemu Ritual. New York: Cornell University Press.

Turner, V. (1969). The Ritual Process: Structure and Anti-Structure. Chicago: Aldine De Gruyter 
Williams, S.J. (2000). Chronic illness as biographical disruption or biographical disruption as chronic illness? Reflections on a core concept. Sociology of Health \& IIIness 22(1), 40-67

Wilmoth, M.C. (2001). The Aftermath of Breast Cancer: An Altered Sexual Self. Cancer Nursing, 24(4), 278-286

Young, I. M. (1990). Throwing Like a Girl and Other Essays in Feminist Philosophy and Social Theory, Indianapolis: Indiana University Press 